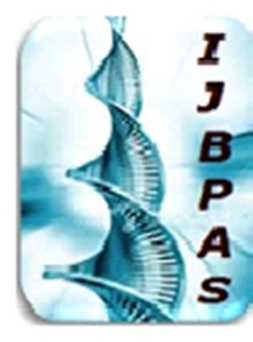

International Journal of Biology, Pharmacy and Allied Sciences (IJBPAS) 'A Bridge Betueen Caboratory and Q Qnder'

\author{
Www.jibpas.com
}

\title{
INHIBITORY EFFECT OF AQUEOUS ROOT EXTRACT OF DECALEPIS HAMILTONII ON ROAT1
}

\section{SANDOPA $\mathbf{D}^{1 *}$, DIVITI $\mathbf{R}^{2}$ AND VEERAPANDIAN $\mathrm{C}^{3}$}

1: Assistant Professor, Department of Pharmacology, Sri Padmavathi School of Pharmacy, Tiruchanur, Tirupati-517503

2: H.O.D \& Principal, Department of Pharmacology, Sri Padmavathi School of Pharmacy, Tiruchanur, Tirupati-517503

3: HOD \& Vice Principal, Department of Pharmacology, SRM College of Pharmacy, SRMIST, Kattankulathur

*Corresponding Author: Dhanunjaya Sandopa: E Mail: dhanuspsp@gmail.com

Received 12 ${ }^{\text {th }}$ March 2021; Revised 15 ${ }^{\text {th }}$ April 2021; Accepted 31 ${ }^{\text {st }}$ May 2021; Available online $1^{\text {st }}$ March 2022

\section{https://doi.org/10.31032/IJBPAS/2022/11.3.5834}

\begin{abstract}
About three quarters population around the world is depended upon traditional medicines for treatment of diseases. The medicinal plants are source of natural product having various phytochemicals. Presence of phenolic acids and other root specific compounds in Aqueous Root Extract of Decalepis hamiltonii, major component in herbal drink, Nannari may also inhibit the hOAT1 transporter and may precipitate herb-drug interaction with hOAT1 substrate drugs. Therefore the study is conducted to evaluate the inhibitory effect of aqueous root extract of Decalepis hamiltonii (AREDH) on rat Oat1, a homologous transporter of human OAT1. The present study was conducted on Albino rats by administration of Decalepis hamiltonii aqueous root extract for 28 days and estimation of plasma concentrations of Para Amino Hippuric acid (PAH) after IV bolus administration on $28^{\text {th }}$ day. The results shows significant decrease in CL \& $\mathrm{k}_{10}$, and significant elevation in $\mathrm{t}_{1 / 2} \beta$, $\mathrm{AUC}_{0-\infty} \& \mathrm{~V}_{\mathrm{ss}}$ of $\mathrm{PAH}$ in test group compared to control group clearly indicates the cumulative inhibitory effect of phenolic acids present in the AREDH. Further, the co-administration of AREDH with any hOAT1 substrate, results in decrease in clearance and increase in the bioavailability and half-life of the substrate drugs. Therefore, if the elevation in plasma concentrations of hOAT1 substrate drugs is within the therapeutic window, the patient may not experience the adverse effects. But, if the plasma concentrations are above the therapeutic window the patient may experience the adverse effects which are not usually observed at the dose of the substrate drug.
\end{abstract}

Keywords: Medicinal plant, Drug interaction, Albino rats, OAT1 transporters, Pharmaceutical drug 


\section{INTRODUCTION}

The use of herbal medicines is gradually growing across the world, but at present very subtle information has been published on herb-drug interaction [1]. The herbal preparations contain active phytochemicals in varying proportions which have tendency like other pharmacologically active moieties to alter the enzymatic systems, transporters and the physiological process when mixed with modern medicines [2]. WHO estimates that about three quarters of world population currently uses herbs and other forms of traditional medicines to treat the diseases [3]. Even as we have entered into the new century with an exciting hope of gene therapy, herbal medicines remain one of the common forms of therapy available to the world population. It is clear that botanical medications have increased in popularity. WHO estimates, the present claim for medicinal plants is - US\$14 billion a year and by the year 2050 it would be - US\$5 trillion [4] and it is estimated that $60-70 \%$ of the American population is taking botanical products, but less than $1 / 3 \mathrm{rd}$ of these persons inform their medical practitioners of such use [5]. At present, our understanding of the interactions between drugs and herbs and between drugs and food is still in its infancy. Some researchers suggest that herb-drug interactions occur less often than predicted [6].

All the medicinal herbs and pharmaceutical drugs are therapeutic at one dose and toxic at another. Interactions between herbs and drugs may increase or decrease the pharmacological or toxicological effects of either each other. Synergistic therapeutic effects may complicate dosing of long-term medications. For example herbs traditionally used to decrease glucose concentration in diabetes could theoretically precipitate hypoglycaemia if taken in combinations with conventional drugs. In addition to this, long term subtherapeutic concentrations of antibiotics leads to the development of resistance by bacteria and further tolerance may be developed by the patient in case of other drugs. Because of these possible herb drug interactions, health care providers need to be aware of herbal supplement use by the patients and the possible interactions with drugs. Moreover, extensive research has to be carried out with most commonly used herbal products for their possibility of precipitating herb-drug interactions. Hence, the health care professionals and public can be alerted about the usage of herbal products when they are under treatment [7]. It is estimated that nine food derived phenolic acids, p-coumaric acid, ferulic acid, gallic acid, gentisic acid, 4- 
hydroxybenoic acid, protocatechuic acid, sinapinic acid, syringic acid, and vanillic acid has inhibitory effect on human organic anion transporter 1 (hOAT1), hOAT2, and hOAT3 transporters [8]. It has been reported that aqueous as well as methanol extracts of Decalepis hamiltonii (Dh) containing abundant phenolics with predominant levels $(20-40 \%$ of total phenolics) of 2-hydroxy -4-methoxy benzaldehyde (HMBA). Other phenolics are vanillic acid (4-hydroxy-3-metoxy benzaldehyde) protocatechnic acid (3,4dihydroxy benzoic acid), gentisic acid (2,5dihydxoxy benzoic acid) syringic acid (4hyroxy-3,5-dimethoxy benzoic acid), caffeic acid (3,4-dihydroxy cinnamic acid), p-ceomoric acid (p-hydroxycinnamic acid),fernlic acid(4-hydroxy-3-methoxy cinnamic acid), cinnamic acid (3-phenyl-2propenoic acid [9]. Other volatiles reported in the $\mathrm{Dh}$ are benzaldehyde, salicylaldehyde, methyl salicylate, benzyl alcohol, 2-phenyl ethyl alcohol, ethyl salicylate and p-anisaldehyde [10]. The Presence of phenolic acids and other root specific compounds in AREDH, major component in herbal drink, Nannari may also inhibit the hOAT1 transporter and may precipitate herb-drug interaction. Therefore, this study is conducted to evaluate the inhibitory effect of aqueous root extract of Decalepis hamiltonii
(AREDH) on rat Oat1, a homologous transporter of human OAT1.

\section{MATERIALS AND METHODS}

\section{Chemicals}

Para Amino Hippuric acid (PAH), PAminobenzoic acid, 4.2\% Perchloric acid, Dichloromethane, Ammonium sulfate, Ethyl acetate, Nitrogen gas and Acetonitirile.

\section{Animals}

Healthy male albino rats of Wister strain weighing $250 \pm 10$ grams were obtained from Raghavendra enterprises, Bangalore, Karnataka, India. They were acclimatized to laboratory conditions for 7 days before dosing and they were housed in stainless steel cages with free access to food and water at a controlled room temperature $24^{\circ} \mathrm{C}$, under 12:12 hr light dark cycles. After one week of acclimatization, the experimental animals were divided randomly into two groups $(n=6)$ and care of animals was taken as per guidelines of Committee for the Purpose of Control and Supervision on Experimental Animals (CPCSEA), department of animal welfare, Government of India.

\section{Collection of plant material}

Roots of the plant Decalepis hamiltonii for the experiment were collected from a vendor in Kurnool town and were authenticated by botanical survey of India, Hyderabad. 


\section{Preparation of plant extract}

One part coarse powder of roots of Decalepis hamiltonii and nine parts of demineralized water at $50^{\circ} \mathrm{C}$ are soaked overnight and filtered on next day. The filtrate was considered as aqueous root extract of Decalepis hamiltonii (AREDH). Weight per ml calculations was done by loss on drying method [11].

Toxicity Studies

Toxicity studies as per the OECD 423 guidelines were done with $200 \mathrm{mg} / \mathrm{kg}$ upto $5000 \mathrm{mg} / \mathrm{kg}$ and found no toxicity at $2000 \mathrm{mg} / \mathrm{kg}$ and $5000 \mathrm{mg} / \mathrm{kg}$. Hence, $1 / 10^{\text {th }}$ of $2000 \mathrm{mg} / \mathrm{kg}$ i.e. $200 \mathrm{mg} / \mathrm{kg}$ was used for the experimentation [12].

\section{Experimental protocol}

The animals were divided into two groups of six animals in each group. Group1 served as untreated control, was administered daily with $2 \mathrm{ml}$ of demineralized water and group 2 rats were treated orally with Decalepis hamiltonii (200mg/kg p.o/day) for 28 days. On $28^{\text {th }}$ day after $1 \mathrm{hr}$ of dosing with demineralized water to the control and AREDH to the test, PAH $(20 \mathrm{mg} / \mathrm{kg})$ was administered through IV as a bolus dose. After that the blood samples $(0.5 \mathrm{ml})$ from retro orbital plexus were withdrawn serially $(5,10,20,35,45$, 60, 90, 120 minutes) under mild ether anesthesia. The clear straw colored serum was separated by centrifugation $(5000 \mathrm{~g}$ for 5min) and stored at $-70^{\circ} \mathrm{C}$ until analysis [13].

\section{Chromatography}

\section{Parameters of optimized method}

- Mode: Isocratic

- Stationary Phase: Phenomenex $\mathrm{C}_{18}$ Column $(250 \mathrm{mmX} 4.6 \mathrm{~mm}, 5 \mu \mathrm{m})$ [14]

- Mobile Phase: 0.1M acetic acid: Acetonitrile (99:1)

Flow rate: $1 \mathrm{ml} / \mathrm{min}$; Detection wavelength: $254 \mathrm{~nm}$; Injection volume: $50 \mu 1$; Internal Standard: Para-Amino Benzoic acid (PABA); Diluent: Mobile Phase

\section{Sample Preparation}

To $200 \mu \mathrm{l}$ of a plasma sample, $100 \mu \mathrm{l}$ of 1 $\mu \mathrm{g} / \mathrm{ml} p$-aminobenzoic acid (PABA) used as the internal standard was added along with a $4.2 \%$ perchloric acid solution. The mixture was vortexed and centrifuged at $13000 \mathrm{rpm}$ for $5 \mathrm{~min}$. The supernatant was transferred to another tube and then supplemented with $200 \mu$ dichloromethane. The tubes were vortexed and centrifuged at $13000 \mathrm{rpm}$ for 5min again, and the supernatant was transferred to another tube which contained $200 \mathrm{mg}$ ammonium sulfate and $200 \mu \mathrm{l}$ ethyl acetate. The tubes were vortexed and centrifuged at $13000 \mathrm{rpm}$ for 5 min once again, and then the supernatant was transferred to another tube. After desiccation under nitrogen gas, the sample was reconstituted with $200 \mu$ of the mobile phase, and $50 \mu \mathrm{l}$ was used for HPLC. The 
concentration range of the standard curve was $0.1 \sim 30 \mu \mathrm{g} / \mathrm{ml}$ [15].

Preparation of Standard Solutions

- A series of standards in the concentration range of $0.1-$ $30 \mu \mathrm{g} / \mathrm{ml}$ using mobile phase were prepared on dilution of aliquots obtained from primary $(1000 \mu \mathrm{g} / \mathrm{ml})$ and secondary stock solutions $(100 \mu \mathrm{g} / \mathrm{ml})[\mathbf{1 6}]$.

- The aliquots were injected into the chromatography system.
- A calibration graph was plotted by taking concentration on $\mathrm{X}$-axis and peak area on Y-axis.

- The graph showed a good linearity with $\mathrm{R}^{2}$ value of 0.9937 (Table 1, Figure 1).

\section{Statistical analysis}

Statistics analysis of the data was done using version 5.0 of prism Graf pad. All the values of the experimental results were expressed as Mean \pm SEM and analyzed by unpaired $\mathrm{T}$ - test for comparison between the two groups.

Table 1: Area of peak of PAH at a concentration range of $0.1 \sim 30 \mu \mathrm{g} / \mathrm{ml}$

\begin{tabular}{|c|c|}
\hline Concentration of PAH $(\mu \mathrm{g} / \mathrm{ml})$ & Area of Peak \\
\hline 0.1 & 255 \\
\hline 1 & 1555 \\
\hline 10 & 7632 \\
\hline 20 & 15739 \\
\hline 30 & 26021 \\
\hline
\end{tabular}

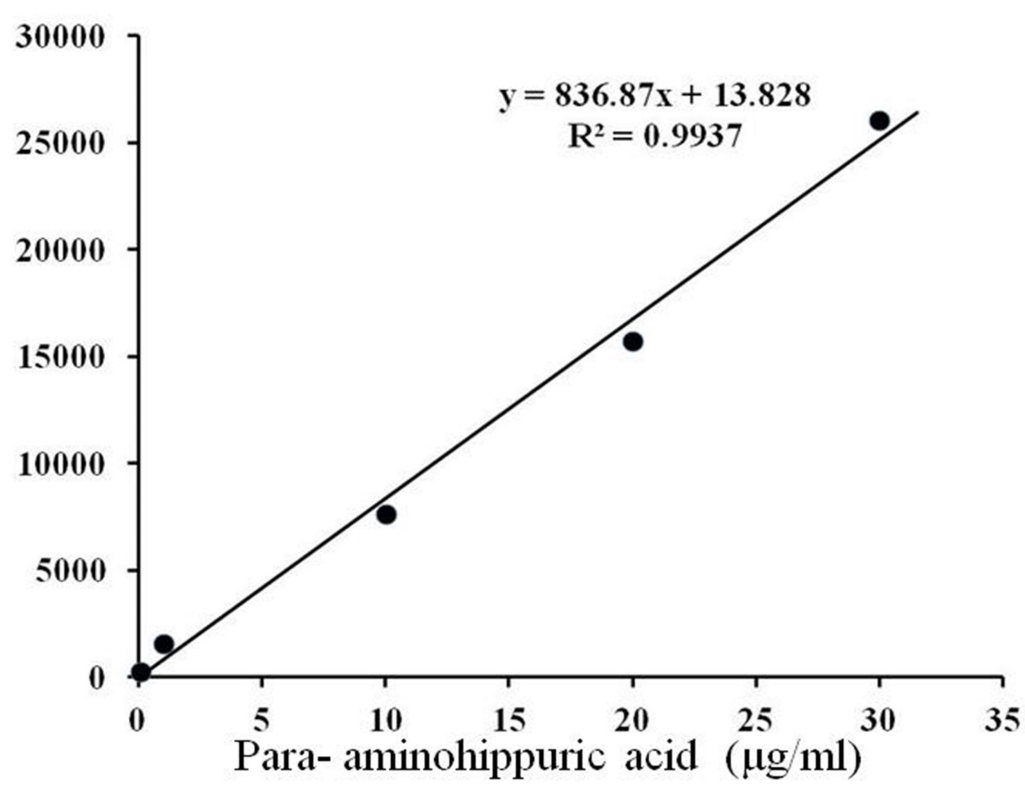

Figure 1: Standard curve of PAH at a concentration range of $0.1 \sim 30 \mu \mathrm{g} / \mathrm{ml}$ 


\section{RESULTS}

\section{Mean plasma Concentration}

Mean plasma concentration of PAH in the blood samples withdrawn at 5, 10, 20, 30, $45,60,90$, and 120 minutes of rats grouped under control and test with their Standard error calculated for six rats. Student unpaired $\mathrm{t}$ - test was applied to compare the mean plasma concentration values of test with standard. Except for the time intervals 05 minutes, the P-values obtained are less than 0.05. Hence there is a significant difference exists in plasma concentrationtime profiles of PAH between control and test (Table 2, Figure 2).

\section{Pharmacokinetics parameters}

Mean data of Pharmacokinetic Parameters $\left(\mathrm{k}_{10}=\right.$ Elimination rate constant, $\mathrm{t}_{1 / 2} \alpha=$ Distribution half-life, $t_{1 / 2} \beta=$ Elimination half-life, $V_{\mathrm{ss}}=$ Steady state Volume of distribution, $\mathrm{V}_{\mathrm{c}}=$ Volume of distribution of Central Compartment, $\mathrm{CL}=$ Clearance, $\mathrm{AUC}_{0-\mathrm{t}}=$ Area under the curve from 0 to time $\mathrm{t}, \mathrm{AUC}_{0 \text {-inf }}=$ Area under the curve from 0 to infinity) of PAH and their standard error calculated for six rats, when given through IV route in rats grouped under Control and Test. Student unpaired $t$ - test was applied to compare the mean pharmacokinetic values of control and test groups. The $\mathrm{P}$ value of $\mathrm{k}_{10}, \mathrm{t}_{1 / 2} \beta, \mathrm{V}_{\mathrm{ss}}, \mathrm{CL}$, $\mathrm{AUC}_{0-\mathrm{t}}$ and $\mathrm{AUC}_{0 \text {-inf }}$ are less than 0.05. Hence, there is a significant difference in these pharmacokinetic parameters of $\mathrm{p}$ aminohippuric acid between control and test. Whereas $t_{1 / 2} \alpha$ and $V_{c} P$-values are more than 0.05 , indicating no significant difference between control and test (Table

\section{3, Figure 3).}

Table 2: Mean Plasma Concentration-Time profile of PAH in Control and Test groups when given through IV route

\begin{tabular}{|c|c|c|c|}
\hline $\begin{array}{c}\text { TIME } \\
(\mathrm{min})\end{array}$ & $\begin{array}{c}\text { MEAN CONCENTRATION } \\
(\mu \mathrm{g} / \mathrm{ml}) \pm \text { STANDARD ERROR } \\
(\mathrm{n}=6)(\mathrm{CONTROL})\end{array}$ & $\begin{array}{c}\text { MEAN CONCENTRATION }(\mu \mathrm{g} / \mathrm{ml}) \\
\pm \text { STANDARD ERROR }(\mathrm{n}=6)(\mathrm{TEST})\end{array}$ & P Value \\
\hline 05 & $\mathbf{8 . 2 1 0} \pm 0.281$ & $\mathbf{8 . 4 1 0} \pm 0.281$ & 1.0000 \\
\hline 10 & $4.543 \pm 0.091$ & $4.972 \pm 0.028$ & 0.0012 \\
\hline 20 & $2.583 \pm 0.1336$ & $3.698 \pm 0.045$ & 0.0001 \\
\hline 30 & $1.788 \pm 0.070$ & $3.022 \pm 0.015$ & 0.0001 \\
\hline 45 & $0.7400 \pm 0.014$ & $2.702 \pm 0.034$ & 0.0001 \\
\hline 60 & $\mathbf{0 . 6 5 8 8} \pm 0.018$ & $2.243 \pm 0.069$ & 0.0001 \\
\hline 90 & $\mathbf{0 . 4 9 1 3} \pm 0.016$ & $1.580 \pm 0.031$ & 0.0001 \\
\hline 120 & $0.4475 \pm 0.018$ & $0.755 \pm 0.038$ & 0.0001 \\
\hline
\end{tabular}




\section{Plasma Conc. Vs Time (IV Bolus of PAH)}

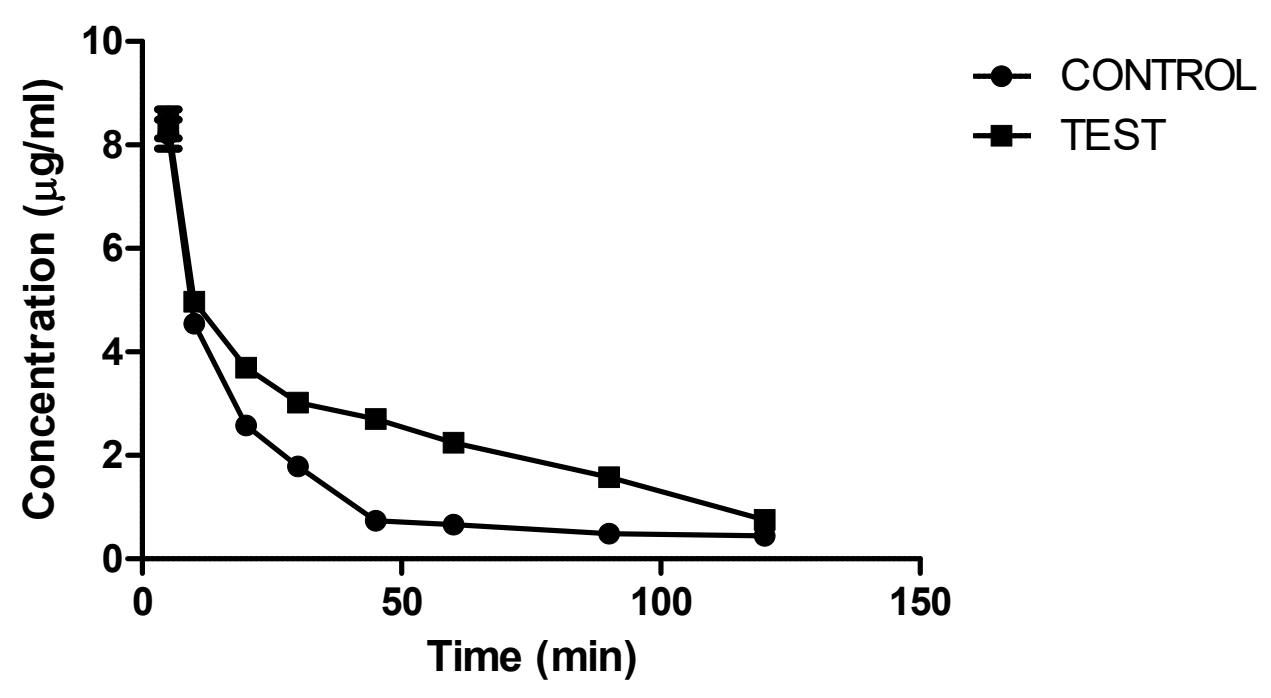

Figure 2: Mean Plasma-Concentration time profile graph with standard error $(n=6)$ of PAH in Control \& Test group rats plotted in normal scale with Graph pad Prism.

Table 3: Pharmacokinetic Parameters of PAH when given through IV route in Control and Test groups.

\begin{tabular}{|c|c|c|c|c|}
\hline S. No. & PARAMETER & CONTROL $(n=6)$ & $\begin{array}{l}\text { TEST } \\
(n=6)\end{array}$ & P VALUE \\
\hline 1 & $k_{10}\left(\min ^{-1}\right)$ & $0.104 \pm 0.013$ & $0.049 \pm 0.005$ & 0.0037 \\
\hline 2 & $\mathbf{t}_{1 / 2} \alpha(\min )$ & $3.020 \pm 0.534$ & $2.492 \pm 0.152$ & 0.3641 \\
\hline 3 & $\mathbf{t}_{1 / 2} \beta$ (min) & $25.05 \pm 3.929$ & $56.62 \pm 1.403$ & 0.0001 \\
\hline 4 & $\mathrm{~V}_{\mathrm{ss}}(\mathrm{ml} / \mathrm{kg})$ & $2.417 \pm 0.241$ & $3.312 \pm 0.111$ & 0.0072 \\
\hline 5 & $V_{c}(\mathrm{ml} / \mathbf{k g})$ & $1.005 \pm 0.146$ & $1.002 \pm 0.119$ & 0.9849 \\
\hline 6 & CL $(\mathrm{ml} / \mathrm{kg} / \mathrm{min})$ & $0.096 \pm 0.002$ & $0.046 \pm 0.000$ & 0.0001 \\
\hline 7 & $\mathrm{AUC}_{0-\mathrm{t}}\left(\mu \mathrm{g} / \mathrm{ml} \mathbf{F}^{*} \mathrm{~min}\right)$ & $205.1 \pm 5.694$ & $425.4 \pm 3.111$ & 0.0001 \\
\hline 8 & $\operatorname{AUC}_{0 \text {-inf }}\left(\mu \mathrm{g} / \mathrm{ml}^{*}\right.$ min $)$ & $209.1 \pm 5.381$ & $430.0 \pm 3.304$ & 0.0001 \\
\hline
\end{tabular}



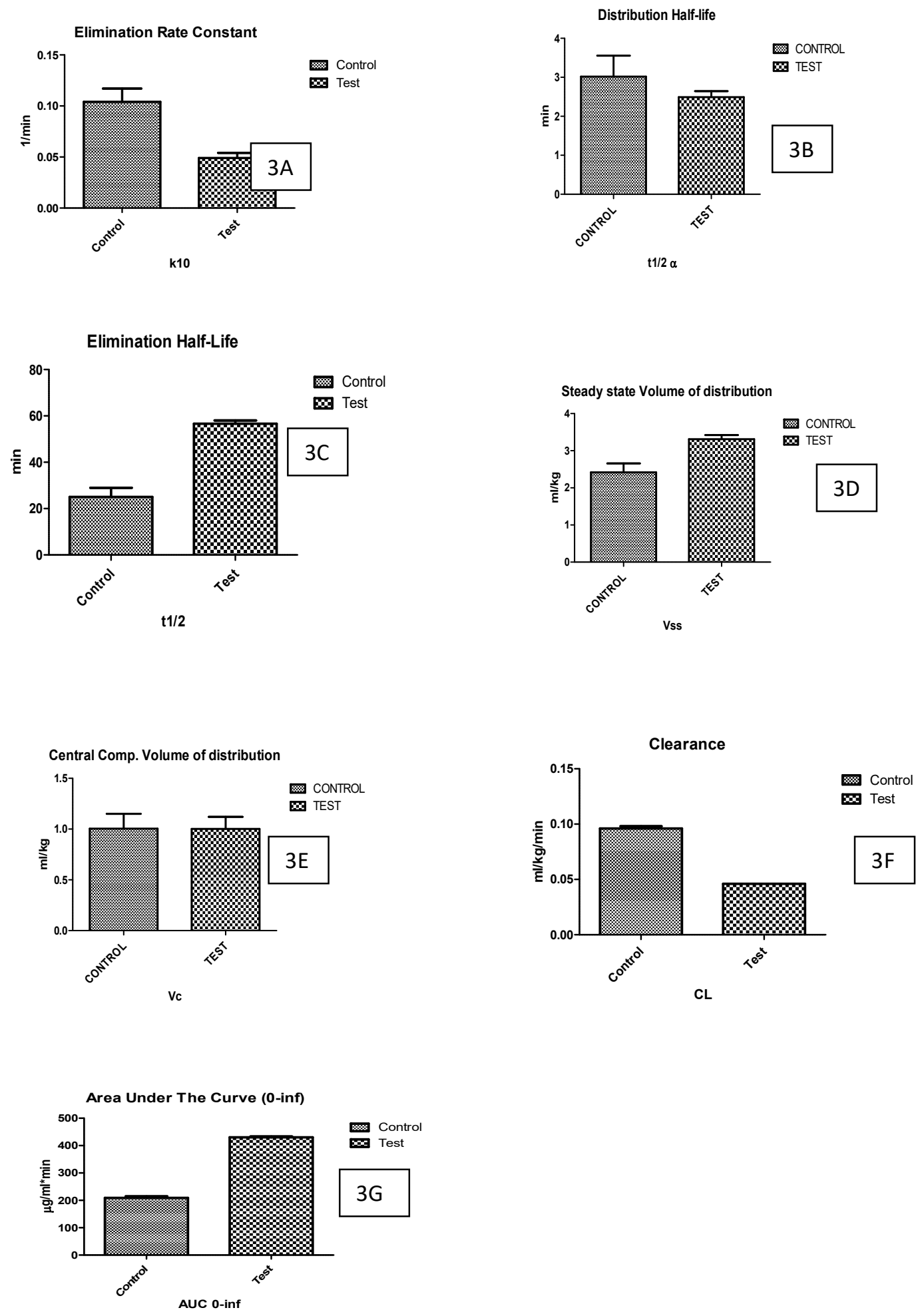

Figure 3: Pharmacokinetic Parameters of PAH when given through IV route in Control and Test groups are shown from $3 \mathrm{~A}$ to $3 \mathrm{H}$ 


\section{DISCUSSION}

Pharmacokinetics of drugs is substantially influenced by the deliberate or passive intake of many chemical substances that man is increasingly being exposed to either in his environment, for medical reasons or as a result of patient's lifestyle. These chemical substances are derived from a variety of sources and include pharmaceutical products, cosmetics, food additives and industrial chemicals. While it is clear that the ingestion of drugs, and to a certain extent food additives is predetermined, a conscious act and many of the chemicals enter the body by more subtle means, as exemplified by the pollution of food chains by insecticides and the accidental (sometimes intentional) exposure to industrial chemicals and solvents from the environment. It is clear that man is either intentionally or accidentally exposed to many chemical substances that have potential to alter drug pharmacokinetics. Accordingly, it is the purpose of this present study to evaluate the inhibition effect of Decalepis hamiltonii, the phenolic acid rich bio-insecticidal plant aqueous root extract - a major component in ayurvedic preparations and summer drink Nannari. To evaluate the hypothesis that, AREDH (phenolic acid rich extract) inhibits the hOAT1 and decreases the elimination of hOAT1 substrate when consumed together and precipitate the herb-drug interaction,
PAH is taken as the probe substrate. Bioavailability of PAH administered through IV route depends on systemic clearance. PAH is cleared by both filtration in glomerulus and secretion by OAT1 in proximal tubules. Hence, altering the activity (induction or inhibition) of OAT transporters may affect the bioavailability of PAH. Animals (rats) were grouped into two 'Control' and 'Test' with 6 rats in each group. Control group and Test group animals received $2 \mathrm{ml}$ of de-mineralized water and AREDH (200mg/kg) respectively for 28 days. On $28^{\text {th }}$ day after treatment, PAH $(20 \mathrm{mg} / \mathrm{kg}) \quad$ was administered as IV bolus and the blood samples were withdrawn from retro-orbital plexus serially $(5,10,20,35,45,60,90 \&$ 120min) and serum was separated by centrifugation for HPLC analysis of PAH. Plasma concentration Vs time plots and the pharmacokinetic (PK) parameters were calculated by using the PK solver software. The PK parameters of PAH were calculated from plasma concentration Vs time profile of each rat in control and test groups $(n=6)$ and mean $\pm \mathrm{SEM}$ was used to compare PK parameters. Student unpaired t-test was used to compare the mean of PK parameters of control and test groups. When plasma concentration Vs time profiles of control group and test groups were observed, there was a rapid fall in the concentration of PAH from $5 \mathrm{~min}$ to $10 \mathrm{~min}$, 
indicates the rapid distribution of $\mathrm{PAH}$ into the tissues and confirms its two compartment kinetics. In addition to this, there was no significant difference in Distribution half life $\left(t_{1 / 2 \alpha}\right)$ was observed. Further, significant decrease in Clearance (CL) and Elimination rate constant $\left(\mathrm{k}_{10}\right)$ of $\mathrm{PAH}$ in test group was observed when compared to CL \& $\mathrm{k}_{10}$ of PAH in control group. As there was a significant decrease in Clearance of PAH in test group, the $\mathrm{PAH}$ retained in the body and significant increase in Elimination half-life $\left(\mathrm{t}_{1 / 2 \beta}\right)$ and $\mathrm{AUC}_{0-\infty}$ of $\mathrm{PAH}$ was observed in test group, compared to $t_{1 / 2 \beta}$ and $\mathrm{AUC}_{0-\infty}$ of $\mathrm{PAH}$ in control group. In addition to this, there was a significant increase in Steady state Volume of distribution $\left(\mathrm{V}_{\mathrm{ss}}\right)$ was observed. All these observations are correlated with the study done. with the individual phenolic acids incubated with $\mathrm{PAH}$, reduced the accumulation of $\mathrm{PAH}$ inside the stably transfected Chinese hamster ovary (CHO-hOAT1) cells, indicating their inhibitory effect on hOAT1 transporter [17]. Hence, the pretreatment with AREDH has generated the anions of phenolic acids, which acted as substrates and inhibitors on rat oat1 (homologous to hOAT1) and inhibited the elimination of $\mathrm{PAH}$ by oat 1 transporter in the proximal tubules of nephron and further, increasing the bioavailability of PAH.

\section{CONCLUSION}

In conclusion, the co-administration of Nannari juice with any hOAT1 substrate (ACE inhibitors, angiotensin II receptor antagonists, diuretics, HMG CoA reductase inhibitors, $\beta$-lactam antibiotics, antineoplastic and antiviral drugs, and uricosuric drugs etc.) results in decrease in clearance and increase in the bioavailability and half-life of the substrate drugs and may precipitate the drug interactions. Further, confirmation is warranted with clinical trials.

\section{ACKNOWLEDGEMENTS}

The authors are thankful to the Dr. M. Venkateswarlu, Dr. B. Pushpa Kumari \& Mrs. M. Hima Saila, Sri Padmavathi School of Pharmacy for their support and encouragement in carrying out this project.

\section{REFERENCES}

[1] Moreira, D., Teixeira, S., Monteiro, M., De-Oliveira, A. and Paumgartten, F. (2017). Traditional use and safety of herbal medicines1. Brazil: Rev. bras. Farmacogn, pp. 248-257.

[2] Hussain, W., Badshah, L., Ullah, M., Ali, M., Ali, A., \& Hussain, F. (2018). Quantitative study of medicinal plants used by the communities residing in Koh-eSafaid Range, northern PakistaniAfghan borders. Journal of Ethnobiology and Ethnomedicine, 14(1). doi:10.1186/s13002-0180229-4 
[3] Joshi Nirali, B. and Shankar, M.B. (2016). Global market analysis of herbal drug formulations. Int. J. Ayu. Pharm. Chem, pp. 59-65.

[4] Aneesh, T., Hisham, M., Sekhar, S., Madhu, M. and Deepa, T. (2009). International market scenario of traditional Indian herbal drugs India declining. International Journal of Green Pharmacy, 3(3), p.184.F

[5] Kuhn, M. (2017). Herbal Remedies: Drug-Herb Interactions. [online] Ccn.aacnjournals.org. Available at: http://ccn.aacnjournals.org/content/ 22/2/22.full.pdf + html? sid=5991 ea 1 8-0e45-4082-8aec-bd37c6296dbf [Accessed 29 Jun. 2017].

[6] Hussain, S. (2011). Patient Counseling about Herbal-Drug Interactions. African Journal of Traditional, Complementary and Alternative Medicines, 8(5S).

[7] Woo, C. S. J., Lau, J. S. H., \& ElNezami, H. (2012). Herbal Medicine. In L.-F. Shyur \& A. S. Y. Lau (Eds.), Advances in Botanical Research (Vol. 62, pp. 365-384). San Diego, CA: Elsevier.

[8] Wang, L. and Sweet, D.H., 2012. Potential for food-drug interactions by dietary phenolic acids on human organic anion transporters 1 (SLC22A6), 3 (SLC22A8), and 4
(SLC22A11). Biochemical

pharmacology, 84(8), pp. 10881095.

[9] Srikanta, B. M., Nayaka, M. A. H., \& Dharmesh, S. M. (2011). Inhibition of Helicobacter pylori growth and its cytotoxicity by 2 hydroxy 4-methoxy benzaldehyde of Decalepis hamiltonii (Wight \& Arn); a new functional attribute. Biochimie, 93(4), 678-688.

[10] Nagarajan, S., Jagan Mohan Rao, L. and Gurudutt, K.N., 2001. Chemical composition of the volatiles of Decalepis hamiltonii (Wight \& Arn). Flavour and fragrance journal, 16(1), pp. 2729.

[11] Srikanta, B. M., Nayaka, M. A. H., \& Dharmesh, S. M. (2011). Inhibition of Helicobacter pylori growth and its cytotoxicity by 2hydroxy 4-methoxy benzaldehyde of Decalepis hamiltonii (Wight \& Arn); a new functional attribute. Biochimie, 93(4), 678-688.

[12] Srivastava, A., Jagan Mohan Rao, L., \& Shivanandappa, T. (2007). Isolation of ellagic acid from the aqueous extract of the roots of Decalepis hamiltonii: Antioxidant activity and cytoprotective effect. Food Chemistry, 103(1), 224-233. 
[13] Sreekumar, P. G., Kannan, R., Yaung, J., Spee, C. K., Ryan, S. J., \& Hinton, D. R. (2005). Protection from oxidative stress by methionine sulfooxide reductases in RPE cells. Biochemical \& Biophysical Research, Communications, 334, 245-253.

[14] Srivastava, A., Shereen Harish, R., \& Shivanandappa, T. (2006). Antioxidant activity of the roots of Decalepis hamiltonii (Wight \& Arn.). LWT-Food Science \& Technology, 39, 1059-1065.

[15] Burckhardt, B. B., \& Laeer, S. (2015). Sample preparation and extraction in small sample volumes suitable for pediatric clinical studies: Challenges, advances, and experiences of a bioanalytical HPLC-MS/MS method validation using enalapril and enalaprilat. International Journal of Analytical Chemistry, 2015, 796249.

[16] Burckhardt, B. B., \& Laeer, S. (2015). Sample preparation and extraction in small sample volumes suitable for pediatric clinical studies: Challenges, advances, and experiences of a bioanalytical HPLC-MS/MS method validation using enalapril and enalaprilat. International Journal of
Analytical Chemistry, 2015, 796249.

[17] Wang, L. and Sweet, D.H., 2012. Potential for food-drug interactions by dietary phenolic acids on human organic anion transporters 1 (SLC22A6), 3 (SLC22A8), and 4 (SLC22A11). Biochemical pharmacology, 84(8), pp. 10881095. 